\title{
Association between Tobacco Smoke Exposure (Environmental and Direct) and Incidence and Control of Bronchial Asthma
}

\author{
S. Dashti ${ }^{1}$, L. Zare ${ }^{2}$, M. Shahmari ${ }^{*}$, F. Dashti ${ }^{3}$, A. Dashti ${ }^{4}$ \\ ${ }^{1}$ Department of Nursing, Faculty of Medical Sciences, Islamic Azad University of Ardabil, Ardabil, Iran \\ ${ }^{2}$ Department of Nursing, Imam Khomeini Hospital, Ardabil, Iran \\ ${ }^{3}$ Islamic Azad University of Ardabil, Ardabil, Iran \\ ${ }^{4}$ Department of Information Technology, Faculty of Technical and Engineering, Ardabil Payame-noor University, Ardabil, Iran \\ Email: ${ }^{\star}$ MehrabanShahmari@gmail.com
}

How to cite this paper: Dashti, S., Zare, L., Shahmari, M., Dashti, F. and Dashti, A. (2018) Association between Tobacco Smoke Exposure (Environmental and Direct) and Incidence and Control of Bronchial Asthma. Open Journal of Nursing, 8, 150-156. https://doi.org/10.4236/ojn.2018.82013

Received: November 1, 2017

Accepted: February 11, 2018

Published: February 14, 2018

Copyright $\odot 2018$ by authors and Scientific Research Publishing Inc. This work is licensed under the Creative Commons Attribution International License (CC BY 4.0).

http://creativecommons.org/licenses/by/4.0/

(c) (i) Open Access

\begin{abstract}
Background: Asthma is a chronic multifactorial disease with high prevalence. Among asthma risk factors, the effect of tobacco smoke exposure on bronchial asthma is still debated. Aim: The aim of this study was to determine the association between environmental and direct tobacco smoke (cigarette and hookah) exposure and incidence and control of bronchial asthma. Materials \& Methods: This descriptive study was conducted on 109 patients with asthma referring to Imam Khomeini Hospital in Ardabil city. Asthma Control Questionnaire was used for evaluating of asthma control. Patients' asthma control was individually evaluated and compared with together with particular attention to history of tobacco smoke exposure. Chi square and Tav-Kendal were used to analyze the data in SPSS15 software. Results: The history of tobacco smoke exposure was found in $31.2 \%$ of the 109 patients. Patients with uncontrolled asthma with $60.6 \%$ constituted the largest volume of all samples. There was no significant correlation between tobacco smoke exposure and asthma occurrence $(\mathrm{P}>0.05)$, also there was not found significant correlation between tobacco smoke exposure and asthma control (Error coefficient $>0.10$ ). Conclusion: According to the results, history of tobacco (cigarette and hookah) smoke exposure (environmental and direct) has no effect on the asthma occurs and control status.
\end{abstract}

\section{Keywords}

Asthma, Tobacco Smoke Pollution, Exposure

\section{Introduction}

Bronchial asthma is a high-prevalence inflammatory chronic disease. According 
to World Health Organization (WHO) estimation, about 20,000 deaths caused by asthma would occur in Middle-East in 2015 [1]. Asthma prevalence in Iran is much higher than international estimation [2]. Bronchial asthma sufferers experience symptoms like wheezing, coughing and shortness of breathes such that it disturbs daily work, repeated awakening at night and boredom in morning [3]. Identification of prevention methods in asthma and providing required trainings for patients, especially by nurses who have the highest contact with patients and community, is a great success in reduction and control of this disease. Asthma is a multifactorial disease i.e. different factors have the role in developing symptoms and attacks of asthma. One risk factor in asthma is exposure to tobacco [4]. Smoking tobacco is one of the problems which threat the human health [5]. Since 1980 up to now, there is discussion about environmental tobacco smoke (ETS) exposure [6]. High percent of people is in environmental tobacco risk exposure [7]. In every 10s, one people dies by diseases caused by tobacco [8]. Studies showed that if one smokes cigarettes (direct exposure) or other person smokes in home (environmental exposure), risk of asthma increases [9]. Exposure to tobacco increases the risk of asthma and worsens its symptoms in patients [10] [11] [12]. Despite studies which consider tobacco smoke as the effective factor in developing asthma, there are studies that their results show no significant association between tobacco smoke and asthma [13] [14]. Whether exposure to tobacco smoke is a risk factor in asthma occurrence is disputed by medical sciences' researchers. Especially, because reviewing literature showed no study about changing asthma control with exposure to tobacco smoke. Increasing community awareness about effects of exposure to environments contaminated with tobacco smoke will help better control of asthma among asthma patients and its prevention among other people. Regarding importance of this issue and inefficiency of studies and contradictory results about effect of tobacco smoke on asthma, this study was conducted which is a descriptive study in order to investigate the association between environmental exposure (smoking by individual) or direct exposure to tobacco smoke with prevalence and control of asthma.

\section{Materials \& Methods}

This is descriptive study which is conducted on 109 adult patients (higher than 12 years) referring to Imam Khomeini hospital in Ardabil. This study was conducted after obtaining certificate from nursing-midwifery faculty of Tabriz University and ethical code number 192 from Tabriz Medical Sciences University ethic committee and coordination of Imam Khomeini hospital authorities in Ardabil for accepting patients referring to this hospital. Statistical society of this study is all asthma patients higher than 12 years old in Ardabil. Inclusion criteria was all patients that their asthma was diagnosed and confirmed by lung disease professional who referred to the Imam Khomeini hospital during study. Exclusion criteria were all patients who were not consented to cooperate with study. 
Asthma disease was diagnosed by expert doctor and based on spirometry para-clinical tests' results and clinical symptoms.

Samples were selected as available and purpose of study was explained for patients. Informed consent form was signed by samples and questionnaires including demographic information and direct and environmental exposure to tobacco smoke and asthma control questionnaire (ACQ) was completed by samples. ACQ was used to determine asthma control condition in patients. Adequacy of asthma control in patients was studied separately and then, they compared in terms of exposure to tobacco smoke. Samples that smoke tobacco or were exposed to tobacco smoke were positive variable. In order to analyze data, SPSS16 statistical data was used. In order to study significance of correlation between tobacco smoke exposure and asthma control, Takendal correlation statistical test was used and Chi-square was used to study the association of exposure to tobacco smoke history with asthma. In this research, confidence level is $95 \%$. In other words, error level $5 \%$ was predicted in calculation of results.

Condition of asthma control in samples was classified by using mean score of 6 questions of ACQ questionnaire. Samples with mean score 0.75 to 1.5 were in controlled and uncontrolled border; below this threshold was controlled and above it was uncontrolled. Validity and reliability of questionnaire was confirmed by these studies [15].

\section{Results}

During study, 109 adult asthma patients entered in the study. Mean age of samples was 40.91 (14.78). Among study samples, $31.2 \%$ have history of exposure to tobacco smoke. Patients with uncontrolled asthma were the largest volume of sample by $60.6 \%$. $37.9 \%$ of samples with uncontrolled asthma, has tobacco exposure history. Table 1 shows asthma condition of study samples.

In order to study significance of correlation between two variables, Takendal statistical test was used. Following hypotheses were tested in order to study that correlation between two variables is statistically significant or not.

$\mathrm{P}$ indicates correlation coefficient between two study variables. Regarding $\mathrm{Ta}-$ ble 2 , by comparing significance level obtained by error factor higher than 0.10 , we can conclude that there is no significant association between tobacco smoke exposure variable and asthma control.

Table 1. Sample asthma, Imam Khomeini Hospital, 2012-2013.

\begin{tabular}{ccc}
\hline & Frequency & \% percent \\
\hline Uncontrolled & 66 & 60.6 \\
Border & 17 & 15.6 \\
Controlled & 26 & 23.9 \\
Total & 109 & 100.0 \\
\hline
\end{tabular}


Table 2. Takendal correlation between variables, Imam Khomeini, 2012-2013.

\begin{tabular}{cccc}
\hline & & Asthma control & Tobacco smoke \\
\hline \multirow{2}{*}{ Asthma control condition } & Correlation coefficient & 1.000 & \\
& Significance level & & \\
Tobacco smoke & Correlation coefficient & -0.018 & 1.000 \\
& Significance level & 0.842 & - \\
\hline
\end{tabular}

In order to study tobacco smoke exposure history association with asthma, Chi-square test was used.

And in order to study this test, agreed table was used. Output of this test included to Table 3. Table 3 is an agreed table which shows expected values and observed values. Chi-square test was used in order to study the association between them. Regarding significance level of test between history of tobacco smoke exposure with asthma ( $\mathrm{p}$-value $<0.05$ ), we can say that there is no significant association between tobacco smoke exposure variable and asthma. Therefore, null hypothesis was confirmed (>0.05). Therefore, positive history of tobacco smoke exposure on asthma has no significant difference.

\section{Discussion}

Regarding results of Table 2 which are obtained Takendal correlation test, there was no association between tobacco smoke exposure and asthma control. Therefore, results of this study show that history of tobacco smoke exposure in asthma suffering patients has no significant effect on controlling their asthma (error factor $>0.10$ ). Statistical results using Chi-square test results show that there was no significant association between tobacco smoke exposure and asthma occurrence ( $\mathrm{p}$-value $<0.05$ ). Therefore, we can say that although $31.2 \%$ of study samples have exposed to tobacco smoke, but there was no significant association between this variable and asthma. Our study results were consistent with results of some researchers. Eagan et al. (2002) studied the asthma occurrence of asthma between smokers but they found no association between smoking and asthma occurrence [13]. Basagana et al. (2001) stated in a study that there is no significant association between cigarettes smoke and asthma and increase in Immune-globulin E caused by this disease [14]. Bazazi et al., in a cross-sectional study on students in Gorgan concluded that parents' smoking is not factor causing and increasing asthma, although it creates wheezing [16]. However, we cannot deny effect of tobacco smoke exposure in developing asthma. In this regard, we can refer to Piipari et al. study that showed asthma risk increases in adults by number of daily cigarettes [17]. According to some researchers, evidences related to adverse effects of cigarettes smoke and asthma are so stable that there is a causal association between these two variables [18]. Results of Karimi et al. study showed that exposure to smoke of cigarettes during childhood increases the risk of Atopic diseases, especially asthma [19]. According to WHO, almost half of world children breathe the tobacco-polluted air which intensifies 
Table 3. Tobacco smoke exposure association with different asthma conditions, Imam Khomeini Hospital, 2012-2013 ( $\mathrm{p}<0.05)$.

\begin{tabular}{|c|c|c|c|c|c|}
\hline & & & \multicolumn{3}{|c|}{ Tobacco smoke exposure history } \\
\hline & \multirow{4}{*}{ Uncontrolled } & $\begin{array}{c}\text { Observed } \\
\text { number }\end{array}$ & 41 & 25 & 66 \\
\hline & & $\begin{array}{c}\text { Expected } \\
\text { number }\end{array}$ & 45.4 & 20.6 & 66.0 \\
\hline & & $\begin{array}{c}\% \text { within } \\
\text { asthma }\end{array}$ & $62.1 \%$ & $37.9 \%$ & $100.0 \%$ \\
\hline & & $\begin{array}{c}\% \text { whiting } \\
\text { tobacco }\end{array}$ & $62.1 \%$ & $37.9 \%$ & $100.0 \%$ \\
\hline & & Observed & 14 & 3 & 17 \\
\hline \multirow{7}{*}{$\begin{array}{l}\text { Asthma } \\
\text { condition }\end{array}$} & & Expected & 11.7 & 5.3 & 17.0 \\
\hline & Border & $\begin{array}{l}\text { \% within } \\
\text { asthma }\end{array}$ & $82.4 \%$ & $17.6 \%$ & $100.0 \%$ \\
\hline & & $\%$ tobacco & $37.6 \%$ & $22.9 \%$ & $60.6 \%$ \\
\hline & & Observed & 75 & 34 & 109 \\
\hline & & Expected & 75.0 & 34.0 & 109.0 \\
\hline & Total & $\begin{array}{c}\% \text { whiting } \\
\text { asthma }\end{array}$ & $68.8 \%$ & $31.2 \%$ & $100.0 \%$ \\
\hline & & $\begin{array}{l}\% \text { within } \\
\text { tobacco }\end{array}$ & $100.0 \%$ & $100.0 \%$ & $100.0 \%$ \\
\hline
\end{tabular}

problems like asthma among them [20]. Brook et al. and Sharifi et al., in separate studies have pointed that exposure of children to smoke of parents' cigarette causes health disorders including asthma [9]-[21]. Results of Abdolmohammadian cross-sectional study showed that there is significant association between asthma symptoms and smoking [22]. Regarding literature review, except $\mathrm{Ab}$ dolmohammadian and Karimi study, in other studies, exposure by tobacco smoke was studied not by hookah but in our study, cigarette and hookah were considered. Most research studied the association between direct and environmental exposure to tobacco smoke by one exposure type but this research studied both of them.

\section{Conclusion}

Final conclusion: in this study, asthma patients were compared in terms of environmental or direct (smoking) exposure or non-exposure with tobacco smoke and effect of this variable on asthma control and occurrence was studied. Regarding result, asthma occurrence and control are not related to tobacco consumption history or exposure with smoke in environment. However, considering the importance of issue and conflicted results of studies, there is need for further studies in order to clarify the accurate association between environmental or direct exposure to tobacco smoke with asthma occurrence and control. 
Therefore, it is suggested that future research studies the asthma occurrence in population exposed to tobacco smoke.

\section{Acknowledgements}

We would like to appreciate research deputy of Tabriz Medical Sciences University for issuing the certificate of this study and funding. We also appreciate Dr. Mohammad Mirza Aqhazadeh for his cooperation in this study. We also appreciate all asthma patients and other people who helped us in this study.

\section{Funding}

This research was funded by Vice chancellor of research at Tabriz University of Medical Sciences.

\section{Ethical Approval Code}

The Ethics Committee of Tabriz University of Medical Sciences approved the study.

\section{Conflict of Interest}

None declared.

\section{References}

[1] World Health Organization (WHO) (2014) Asthma Prevalence (Internet). Regional Office for the Eastern Mediterranean, Cairo. http://www.emro.who.int/health-topics/asthma/index.html

[2] Masoli, M., Fabian, D., Holt, S. and Beasley, R. (Eds.) (2004) The Global Burden of Asthma. University of Southampton, United Kingdom, 469-478.

[3] Cochrane, G.M. and Rees, P.J. (1989) A Color Atlas of Asthma. Mosby, America.

[4] Salemi, S. and Shaban, M. (2008) Breathing and Gas Exchange. In: Smeltzer, S., Bare, B., Hinkle, J. and Cheever, K., Eds., Brunner \& Suddarth's Textbook of Medical Surgical Nursing, $11^{\text {th }}$ Edition, Salemi Jamenegar, Tehran, 219.

[5] David, M. (2005) Harrisons Principles of Internal Medicine. 16th Edition, McgrawHill Medical Press, New York, 2406-2418.

[6] Tweedie, R.L. (2006) Environmental Tobacco Smoke (ETS) in: Encyclopedia of Environmetrics. 2nd Edition, Wiley Online Library, Hoboken. https://doi.org/10.1002/9780470057339.vae042

[7] Ahmadizadeh Fini, A., Aghamolaei, T., Dehghani, M., Zare, S. and Madani, A. (2012) Environmental Tobacco Smoke (ETS) Exposure in People over 15 Years Old, Bandar Abbas, Iran. Medical Journal of Hormozgan University, 1, 42-48.

[8] Mohamad, K., Noorbala, A., Majdzade, S. and Karimloo, M. (2001) Trend of Smoking Prevalence in Iran from 1991 to 1999 Based on Two National Health Surveys. Hakin Journals, 3, 290-294. (Full Text in Persian)

[9] Sharifi, L., Pourpak, Z., Bokaie, S., Karimi, A., Movahedi, M., Gharaghozlou, M., et al. (2009) Childhood Asthma Prevalence and Parents' Daily Cigarette Smoking: A Case-Control Study. Tehran University Medical Journal, 9, 655-660. (Full Text in Persian) 
[10] Strachan, D.P. and Carey, I.M. (1995) Home Environment and Severe Asthma in Adolescence: A Population Based Case-Control Study. BMJ, 311, 1053-1056. https://doi.org/10.1136/bmj.311.7012.1053

[11] Strachan, D.P. and Cook, D.G. (1998) Health Effects of Passive Smoking. Parental Smoking and Childhood Asthma: Longitudinal and Case Control Studies. Thorax, 53, 204-212. https://doi.org/10.1136/thx.53.3.204

[12] O'Connell, E.J. and Logan, G.B. (1974) Parental Smoking in Childhood Asthma. Annals of Allergy, 32, 142-145.

[13] Eagan, T.M., Bakke, P.S., Eide, G.E. and Gulsvik, A. (2002) Incidence of Asthma and Respiratory Symptoms by Sex, Age and Smoking in a Community Study. The European Respiratory Journal, 19, 599-605. https://doi.org/10.1183/09031936.02.00247302

[14] Basagaña, X., Sunyer, J., Zock, J.P., Kogevinas, M., Urrutia, I., Maldonado, J.A., et al. (2001) Incidence of Asthma and Its Determinants among Adults in Spain. American Journal of Respiratory and Critical Care Medicine, 164, 1133-1137. https://doi.org/10.1164/ajrccm.164.7.2012143

[15] Juniper, E.F. (2012) Asthma Control Questionnaire. Background, Administration and Analysis. QOL Technologies Ltd., 14.

[16] Bazazi, H., Gharagozlou, M., Kasaei, M., Parsikia, A., Zahmatkesh, H., Alikhani, L., et al. (2003) Association between Parental Smoking and Prevalance of Asthma and Wheezing in School Children in Gorgan. Pejouhandeh, 4, 259-263.

[17] Piipari, R., Jaakkola, J.J., Jaakkola, N. and Jaakkola, M.S. (2004) Smoking and Asthma in Adults. The European Respiratory Journal, 24, 734-739. https://doi.org/10.1183/09031936.04.00116903

[18] Cook, D.G. and Strachan, D.P. (1997) Health Effects of Passive Smoking. 3. Parental Smoking and Prevalence of Respiratory Symptoms and Asthma in School Age Children. Thorax, 52, 1081-1094. https://doi.org/10.1136/thx.52.12.1081

[19] Karimi, M. and Mirzaei, M. (2008) Correlation between Cigarette Smoke Exposure and Prevalence of Asthma and Allergiy Symptoms in Children Yazd. Medical Journal of Hormozgan University, 4, 219-295. (In Persian)

[20] WHO (2007) 10 Facts about Tobacco and Second-Hand Smoke.

[21] Brook, S.J., Zhang, C. and Fagan, P. (2008) Exposure to Parental Cigarette Smoking and Child Problem Behaviors: A Longitudinal Study. Journal of Child and Family Studies, 17, 372-384. https://doi.org/10.1007/s10826-007-9147-0

[22] Abdolmohammadian, S. (2014) The Survey for Prevalence of Respiratory Symptoms Compatible with Asthma in Ardabil (Dissertation). Ardabil University of Medical Sciences, Ardabil, 94 p. 